\title{
Composition of scrub-type cosmetics from the perspective of product ecology and microplastic content
}

\author{
Anna Piotrowska ${ }^{1} \cdot$ Olga Czerwińska-Ledwig ${ }^{1} \cdot$ Marta Serdiuk $^{2} \cdot$ Katarzyna Serdiuk $^{3} \cdot$ Wanda Pilch $^{1}$
}

Accepted: 3 October 2019 / Published online: 16 March 2020

(c) The Author(s) 2020

\begin{abstract}
Objective Civilisational progress causes bigger and bigger interference in the natural environment. The demand for plastics and their production is constantly growing what is the source of wastes. One of the sources of such waste is cosmetic industry. The main source of fragmented polyethylene is the generally used mechanical peelings.

Methods The analysis included 130 scrub-type cosmetic preparations available in the Polish market. Proportional shares of the preparations with polyethylene, natural or mixed abrasive ingredient were determined. The types and frequencies of using natural abrasive materials and biodegradable polymers were characterised. It was analysed if the professional and generally available products differ in this respect.

Results Among the analysed cosmetics, 72 (55\%) included polyethylene, and for professional cosmetics, this proportion was 100. Compositions of drugstore cosmetics are varied, with many abrasive substances of natural origin, and only sometimes with polyethylene.

Conclusions The differences observed between generally available cosmetics and professional cosmetics are surprising and indicate a greater ecological awareness of individual clients. The problem will be raised in the coming years more and more frequently, and, as proved by this analysis, manufacturers of professional cosmetics are not ready for this yet, and they have no alternative ecological solutions.
\end{abstract}

Keywords Cosmetic products $\cdot$ Abrasives $\cdot$ Marine pollution $\cdot$ Biodegradative cosmetic ingredients

\section{Introduction}

Polymers are macromolecular chemical compounds of natural or anthropogenic origin, consisting of simple-form molecules-monomers - connected in linear or branched chains. Polymers are produced as a result of polycondensation or polyaddition types of polymerisation reaction. Before the twentieth century, they were only known as compounds coming from the natural environment (nucleic acids, proteins,

Anna Piotrowska

anna.piotrowska@awf.krakow.pl

1 Department of Chemistry and Biochemistry, Institute for Basic Science, University of Physical Education, Krakow, Poland

2 Science Club by Department of Chemistry and Biochemistry, University of Physical Education, Krakow, Poland

3 Institute of Chemistry, Environmental Protection and Biotechnology, Jan Dlugosz University, Czestochowa, Poland starch and other polysaccharides, latex). The era of plastics started in the second half of the nineteenth century. The first plastics of this type include celluloid developed in 1855 by Alexander Parkes, and rubber obtained by modifying natural rubber (caoutchouc) [1]. The first plastic manufactured in bulk was bakelite based on phenol-formaldehyde resin. The production technology was developed by Leo Baekeland in 1907. In the 1930s, polyvinyl, polyamide, polyethylene and polyester plastics started to be manufactured. However, the dynamic development of plastic industry really started after the end of World War II, and it has continued until today. Currently, plastics are the popular materials indispensable to every branch of economy.

According to statistical data, the most plastics are intended for packaging. In Europe, in 2016, 1105 thousand tonnes of packaging was manufactured, which was an increase by 75 thousand tonnes in comparison with 2015 and 120 thousand tonnes in comparison with 2014 [2]. The runners-up are as follows: construction, automotive, energy and electrotechnical industries [2,3]. The data indicate 
that the most of the manufactured plastics are hydrocarbon derivatives, so the ones with the longest time of degradation.

Managing used plastics, which are brought to waste dumps in the form of municipal and industrial waste, is becoming a global problem. Plastic, often less dense than water and with hydrophobic properties, is transported by rivers and finds its way to seas and oceans. Oceanic islands of plastic garbage are thus a worldwide problem. The biggest garbage islands are located in the Northern Pacific, between California and Hawaii, and between Hawaii and Japan.

It is difficult to estimate the amount of microplastics that end up in inland waters and seas every year. It is estimated that approximately 40 tonnes of microplastics is introduced every year to the Baltic Sea alone [3, 4].

Removing waste of this type from the environment can be performed in three basic ways: recycling, incineration and degradation with biodegradation. Recycling, i.e. reintroduction of the waste material for use, seems to be the best solution. In Europe, approximately $25 \%$ of waste is recycled [5]. Some of plastic waste is burned. This way of waste disposal, however, is controversial due to the fact that toxic gases can get through to the atmosphere, specifically dioxins, furans, nitric oxides, $\mathrm{SO}_{2}$ and ashes containing heavy metals, mostly cadmium and mercury. According to EU regulations, incineration plants have to be equipped with afterburner chambers, which, however, significantly raise costs. The most waste still remains in dumps-55.9\% [2]. The time they stay in the environment varies, depending on their susceptibility to degradation processes. It consists in decomposition of macromolecules into fragments with smaller mass due to the influence of physical, chemical and biological factors. Decomposition of plastics is always initiated by abiotic factors, which can be divided into physical (temperature, ultrasounds, humidity, ionising radiation, electromagnetic radiation) and chemical (oxidation taking place most frequently with molecular oxygen, hydrolysis, i.e. decomposition of chemical bonds as a result of reactions with water, acids, bases) [5].

Biodegradation is decomposition of a macromolecular material by live organisms. In this process, the dominant role is played by bacteria, algae, protozoans and fungi [6]. An introduction to biodegradation is mechanical fragmentation of the material. The second stage is proper biodegradation resulting from a series of enzymatic reactions. Natural, synthetic polymers used as dissolvable surgical stitches, and pharmaceutical capsules, butyric, valeric and lactic polyacids are subject to full biodegradation. Generally, this process is favoured by the presence of additional functional groups, smaller molecular mass, hydrophillic properties and dominance of amorphic over crystalline structure. However, it is inhibited in plastics that are quite hard, with branched chains and with only carbon-carbon bonds [7].
Decomposition of polymers by microorganisms is much faster in the presence of oxygen. In anaerobic conditions, biodegradation, even in the case of natural polymers, is much slower and follows complex mechanisms, and in the case of synthetic polymers, even the relatively easy degradable ones, like polyurethanes, is practically completely inhibited [6, 7].

The most problematic polymers from the perspective of biodegradation are polyolefins. The most popular representative of this group of compounds is polyethylene, which from 1966 takes the first place among the synthetic materials manufactured in the world [2]. It is estimated that plastics manufactured on the basis of polyethylene remain in the environment even up to 500 years [6]. Resistance to the deteriorating influence of the environment is explained by the chemical structure of these polymers. Polyolefins do not have additional functional groups; therefore, their photodegradation, which is necessary to initiate biodegradation, progresses more slowly. They belong to the group of hydrophobic compounds, and also, their big molecular mass additionally hampers their decomposition. Polyethylene with mass over 1000 daltons is considered completely non-degradable. Only significant decrease of molecular mass enables decomposition by microorganisms [5-7].

\section{Microplastics and the water environment}

$10 \%$ of the general annual production of PE ends up in oceans, where degradation can take even several hundred years [4]. Frequently, decomposition is only partial and in the ocean depths, even after such a long time, long-unwanted bits are drifting, only to be joined by new ones every day. Plastics are carried with storm water, sewage, river currents and by land waste transportation by wind [4].

Waste made up of plastics have been found even in high latitudes and in oceanic deeps. Only a few years ago, there were no available data regarding plastic microparticles in the polar regions, and the water column tests in the Arctic Ocean suggested that these wastes are not transported to this region [8]. However, the later analysis of ice core revealed the presence of microplastics in the range of 38 to 234 particles/ $\mathrm{m}^{3}$ [9]. A double of this value was recorded in the Pacific [10]. Plastics floating on the surface of Antarctic and Arctic water were also observed [11, 12], and they were found in the Arctic deep bottom [13] and in the stomachs of birds in the Canadian Arctic [14, 15].

Studies show that at least 267 animal species directly interacts with artificial waste, and approximately 600 species is indirectly exposed to it. Micro- and macroplastics also have the property of being accumulated in tissues, thus potentially travelling to the higher levels of trophic chain, ending up even in human body. 
The presence of microplastics in the alimentary tracts of sea animals and birds living in coastal areas can lead to mechanical injuries, proliferation and, as a result, to death, not only of young animals. Round parts can block the pylorus connecting stomach with small intestine, thus causing an occlusion of the whole alimentary tract. The presence of artificial elements in the stomach also decreases its volume and causes false feeling of satiety [16]. Plastic microparticles floating in seas and oceans fit the size of food of phytoplankton and zooplankton. Pacific krill is a representative of the second plankton group. Finding plastic particles with the size of $31.5 \mu \mathrm{m}$, it mistakes them with its food and eats them. The ingested polyethylene particles of the aforementioned size are fragmented in krill's body and excreted in the form of nanomolecules smaller than $1 \mu \mathrm{m}$, which, as a result of endocytosis, can permeate through cell membranes [17]. This can mean that in the future, we will have an even bigger problem than microplastic.

Heavy metals like cadmium, lead and chromium can accumulate in microplastic waste and reach the organisms of sea fauna with food. The surface of microplastics is also a good habitat for pathogenic bacteria.

\section{Cosmetics as a source of pollution with microplastics}

Plastics, apart from packaging for cosmetics, are part of scrub-type cosmetics, toothpastes, etc. Studies conducted in Denmark in 10 different waste treatment plants showed that along with the filtered water, 600 to 3100 tonnes of microplastics gets released to the environment every year. In the United States, approximately 8 billion particles of microplastics are released to the water environment from waste treatment plants every day. Studies conducted by Liebezeit and Dubaish [18] prove that the main source of microplastic pollution of seas and oceans is cosmetic products. Subsequent studies have proved that cosmetics used for mechanical exfoliation are the basic source [19].

\section{Aim of presented study}

The aim of the study was to analyse the ingredients lists of scrub-type cosmetics available in Poland from the perspective of their ecology. It was analysed if products intended for professional use differ in this regard from drugstore cosmetics.

\section{Results and discussion}

Of the 130 randomly selected cosmetics, the number of products with natural composition was $58(44.6 \%)$, and the number of products with polyethylene content was 50 (38.5\%). Twenty-two cosmetics (19.9\%) included both polyethylene and natural-origin abrasives (Fig. 1). Among the ones intended for use in professional aesthetic parlours, the composition of every one of them included polyethylene $(100 \%)$. A significant difference was shown between the tested groups $(p=0.0000)$.

Among the cosmetics with polyethylene, 22 (27.5\%) included also ingredients of natural origin. Most frequently, these were crushed or whole seeds (27.3\%) and microcrystalline cellulose (22.7\%). The less frequent were nut shells, aluminosilicates, pumice and sea salt $(9.1 \%$ each). In single case, the presence of silica, diatoms, crystalline wax, kaolin, diamond powder, sugar and bamboo particles $(4.5 \%)$ was observed.

Of the 22 cosmetics of mixed composition, 17 (77.3\%) additionally had 1 type of abrasive material of natural origin, 4 products (18.2\%) had 2 types, and only $1(4.5 \%)$ of them had 3 natural elements with exfoliating properties (Fig. 2).

Among the cosmetics with natural composition of exfoliating materials, the dominant exfoliating materials are seeds and pips (60.4\%), sugar (39.7\%) and salt of various origin (25.9\%). Less frequent are shells, aluminosilicates, kaolin, polylactic acid and microcrystalline cellulose. Of the 58 cosmetics, only in singular cases the presence of tree bark, silica, corundum, pumice and crystalline wax was found.

The analysis of the inclusion of seeds, salt and ground pips in the composition of fully natural and mixed products has not shown significant differences $(p=0.4625)$.

Among the cosmetics with composition without polyethylene, 27 products $(46.6 \%)$ included only 1 abrasive material, $25(43.1 \%)$ had 2 such elements in their composition. In 4 cosmetics (6.9\%), 3 types of exfoliating materials of natural origin found. Two products (3.4\%) showed the presence of 4 and more of such materials.

The statistical analysis of the frequency of using 1,2 or 3 exfoliating materials in one cosmetic preparation for cosmetics with natural and mixed composition indicated the presence of significant differences $(p=0.0001)$, and the bigger number of materials was indicated for the preparations

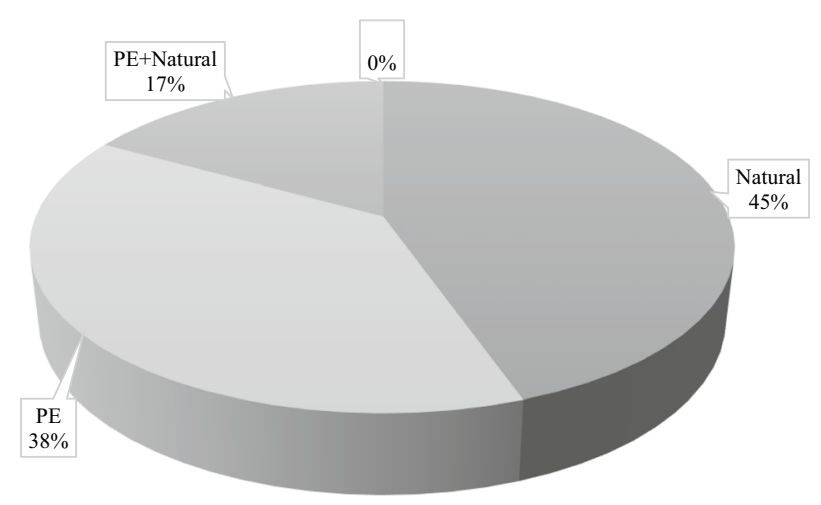

Fig. 1 Cosmetics containing polyethylene (PE), natural and mixed $(\mathrm{PE}+$ natural $)$ scrub ingredients 


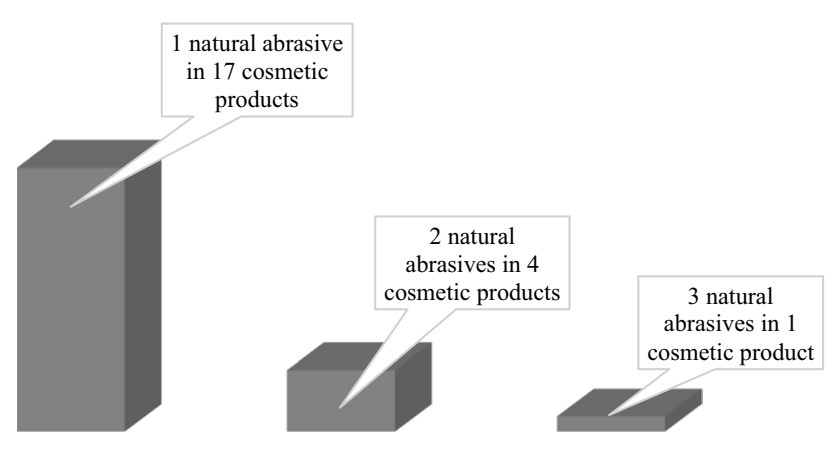

Fig. 2 The quantity of natural abrasives in cosmetics containing polyethylene

with mixed natural-synthetic composition of exfoliating materials.

Of the 130 cosmetics, 74 were selected from various manufacturers. Thirty $(40.5 \%)$ of them had only cosmetics with polyethylene, 29 (39.2\%) with fully natural composition, and $9(12.2 \%)$ were mixed in this regard. Three (4.1\%) companies manufacture cosmetics with microplastics and cosmetics with materials of natural origin mixed with synthetic materials. Two (2.7\%) companies in this random selection had natural and mixed cosmetics. Only 1 manufacturer $(1.4 \%)$ produces cosmetics with all possible composition modifications.

\section{Discussion}

Exfoliation is a procedure based on removing dead epidermis from the surface of skin. It is performed with microdermabrasion treatment and by means of chemical and mechanical peelings. The latter are especially popular due to the simplicity of their performance and the possibility of performing them in home conditions. They are characterised by gel/emulsion consistency and the content of abrasive granules of various sizes, hardness and shapes. Every one of them, depending on their purpose, can also include a different quantity of exfoliating particles.

In paper analysing physicochemical properties of 10 scrub-type cosmetics available in Spain, it was indicated that all analysed products showed the presence of polyethylene [20]. They contained white particles visible to the naked eye. They had an irregular shape, in individual cases spherical, light brown, blue and dark brown colour. Microplastics present in facial peels had a very wide particle size, from 5 to $2 \mathrm{~mm}$. In other works on the particle size of microplastics in the body scrubs, similar or greater results are indicated [21-24].

In our study, randomly selected products were analysed with regard to their composition, containing polyethylene, constituted $38.5 \%$ of all the analysed products. This is a smaller number in comparison with the number of preparations with natural composition, which were $44.6 \%$. However, taking into consideration the cosmetics with ingredients of natural origin, constituting $17 \%$ of the identified product base, the proportion of peelings including in their compositions polyethylene increases to $55.5 \%$. It is surprising that $100 \%$ of the cosmetics intended for use in professional aesthetic cosmetology parlours included polyethylene. From the practical point of view, there is no alternative for PE in the Polish market of professional cosmetics. No preparation was found with an abrasive factor being at least polypropylene. Of the 130 analysed preparations, only in two of them their manufacturers proposed polylactic acid (PLA) as abrasive material-a polyester polymer obtained from corn or sugar beet. It can be an environmentally friendly alternative for hydrocarbon polymers [25]. From the perspective of physical properties, polylactic acid granulate is close to polyethylene. However, it is not frequently used in cosmetic preparations.

Presumably, the way to limit the pollution of natural environment can be peeling preparations of mixed composition. The presence of the addition of natural ingredients in this type of products influences the decreased content of polyethylene. However, such presumptions cannot be unambiguously confirmed, as companies do not provide the data regarding the amount of the introduced polyethylene on packaging of their products. In the 72 discussed preparation with this polymer in their composition, in only one case the manufacturer included the information about it. Basing the formula of exfoliation preparations on ingredients of natural origin, apart from the undoubtedly beneficial effect on the condition of the natural environment, allows for significant broadening of the spectrum of applications of the offered products. Both the ingredients of organic origin, often of polymer structure, and inorganic compounds are used. A numerous group are seeds (raspberry, blackberry, nigella, flax, cannabis, poppy, birch, opuntia), ground grain, rice, coffee, pumpkin seeds, ground shells of various nuts, apricot pips, and saccharose and microcrystalline cellulose. The latter is the most frequently used additive in mixed-composition peelings. Using so diverse ingredients, with different hardness and fragmentation, enables broad application possibilities in products requiring the use of relatively hard and porous abrasive materials (foot peelings) and the very gentle ones (facial peelings). This group is limited by a notably higher index of allergenicity of plant materials in comparison with PE.

Analysing a cosmetic for the hardness of abrasive particles, one can use a five-point scale, where 5 means that the exfoliating fragments have aggressive activity, and the preparations marked with number 1 are intended for face or sensitive parts of the body, and they usually include flower petals, leaves and gently exfoliating pips. The same abrasive properties will be shown by preparations with oval-shaped 
particles. The more irregular the shape, the more efficient the exfoliation. The role of abrasive material can be played by various man-made or natural-origin ingredients.

In the case of inorganic compounds, one can also observe big diversity of materials with regard to their hardness. The softest include kaolin, other aluminosilicates and sodium chloride (2-3 in Mohs scale). Medium-hardness abrasive agents are pumice (6 in Mohs scale) and silica (7 in Mohs scale). Corundum or even diamond powder are used as the hardest exfoliating materials (9 and 10 in Mohs scale, respectively). It should be noted that the different types of aluminosilicates used by manufacturers, due to the inclusion of microelements (compounds of iron, manganese, magnesium), have beneficial effect for the skin.

The analysed cosmetics came from 74 different manufacturers. This high number of manufacturers ensures significant diversity of the offered products and enables satisfying various needs and preferences of the customers. It should be noted that among the manufacturers, there is a clear tendency to specialise in the type of offered peelings. As many as 30 companies proposed products including polyethylene granules as the only abrasive agent. The group of manufacturers specialised in only natural additions was similar. Only nine manufacturers offered products including at the same polyethylene and another, natural peeling ingredient. Only three manufacturers had an offer comprising at the same time cosmetics with polyethylene and cosmetics with natural abrasive ingredients apart from PE. Two companies manufactured natural and mixed peelings, and only one offered a full range of products (natural, mixed and with polyethylene). The fact that there were no manufacturers offering peelings based on polyethylene, and at the same time, offering natural products was very interesting. Also, it should be pointed out that sometimes in sales points products with mixed composition are located in a way that can suggest this are completely natural products, misleading buyers. On some packaging, there was information placed centrally saying sugar peeling or salt peeling, suggesting that in the purchased preparation the only exfoliating agent is saccharose or salt. In reality, these products also included polyethylene microgranules.

The companies manufacturing only natural preparations are largely small family companies, manufactories and new manufacturers in the market. Peelings with polyethylene are manufactured mostly by big concerns with much bigger distribution capabilities and sales network. Products of small companies are available often in only a small number of regional points of sale.

Studies conducted all over the world enabled visualising the scale of the problem and provided bases for taking up actions oriented at limiting, and then totally banning the use of microplastics in cosmetic products. The first to act were Dutch organisations North Sea Foundation and
Plastic Group Foundation in 2012, which developed an app for smartphones, available at http://get.beatthemic robead.org/, which allows to easily check whether a given product has microgranules. German society BUND (Bund für Umwelt und Naturschutz Deutschland) published a list of products with synthetic polymer particles. In 2013, the European Commission published the "Green Book" of plastic waste, including microplastics [26]. In 2014, the Netherlands, Austria, Luxembourg and Sweden brought a project of banning the use of microgranules in cosmetics and detergents to the European Commission [27].

These actions contributed to changes in legislation [4, 28-31]. The first one to ban selling products with microplastics was the American state of Illinois in 2014. Since July 2015, similar regulations have been introduced in Canada. The Act prohibiting manufacturing such cosmetics has been enforced in the USA since 1st July 2017, and on 1st July 2018 an Act on ban trade became effective. In Europe, since January 2018, manufacturing of cosmetic products with microplastics has been banned in the United Kingdom, and since the end of June 2018, this has been extended to sales. Similar regulations, unfortunately, have not been introduced in the European Union. Also, Poland has not taken up appropriate actions towards this goal. Based on the analysis of the gathered data regarding manufacturers and the offered preparations for exfoliation, one can conclude that in our country, the situation related to the threat to the environment posed by microplastics is not optimistic.

As there still are no proper legal regulations limiting, and, consequently, preventing manufacturing and trading preparations with polyethylene, proecological actions increasing customer awareness are necessary, so that they can select product fully informed. This may be not much, but to paraphrase the words of Leibniz, it is always better to do something rather than do nothing. The main sources of MP environment pollution are uncontrolled processes, such as abrasion and degradation of larger plastic products. However, the effect of microplastics from cosmetic products is far from being negligible. This fraction can be relatively easily reduced; therefore, it is necessary to officially forbid the use of cosmetics that are the source of this type of pollution. The cosmetics which are rinsed after use (mostly scrubs, toothpastes) are already starting to be controlled in this respect, but other cosmetic products remain a problem. Guerranti et al. [32] also indicated the need to harmonise the methods describing the forms of microplastics, their impact on the environment and biodegradation. Only such research will be an appropriate base to influence and enforce changes in the legislation leading to exclusion of MP in cosmetics. 


\section{Materials and methods}

A total of 130 exfoliating products available in drugstores and products intended for use in professional aesthetic parlours were selected. Their composition was analysed for the content and type of microplastics, as well as other abrasives of natural origin. The analysis also included the possibilities of replacing synthetic polymers in this type of products.

\section{Statistical analysis of the results}

The STATISTICA 13.1 (StatSoft, Polska) software was used for statistical analysis. The frequency and numbers of specific variants were included. The chi-squared test $\left(\chi^{2}\right)$ was used to evaluate the relation. The significance level of 0.05 was assumed.

\section{Conclusions}

1. Fifty of the 130 randomly selected scrub cosmetics included only polyethylene, and another 22 included polyethylene with natural abrasive materials.

2. The products intended for professional parlours include only microplastics.

3. The range of natural abrasive materials is wide, and it includes ingredients of various level of hardness. Technologically, they can be processed to different granularity, thus modulating their potency. A significant difference was indicated in the amount of exfoliating materials among the products with natural ingredients and preparations with microplastics.

4. Companies manufacture cosmetics with various compositions, and generally no company specialises in creating products with one type of composition. The offer directed to professional recipients is not adjusted to the changing demands of ecologically aware recipients.

Acknowledgements The research was financed from the authors' own funds.

\section{Compliance with ethical standards}

Conflict of interest Anna Piotrowska, Olga Czerwińska-Ledwig, Marta Serdiuk, Katarzyna Serdiuk, and Wanda Pilch declare that they have no conflict of interest.

Ethical approval This article does not contain any studies with human participants or animals performed by any of the authors.
Open Access This article is licensed under a Creative Commons Attribution 4.0 International License, which permits use, sharing, adaptation, distribution and reproduction in any medium or format, as long as you give appropriate credit to the original author(s) and the source, provide a link to the Creative Commons licence, and indicate if changes were made. The images or other third party material in this article are included in the article's Creative Commons licence, unless indicated otherwise in a credit line to the material. If material is not included in the article's Creative Commons licence and your intended use is not permitted by statutory regulation or exceeds the permitted use, you will need to obtain permission directly from the copyright holder. To view a copy of this licence, visit http://creativecommons.org/licenses/by/4.0/.

\section{References}

1. Rzymski WM (2002) Natural rubber and selected products of its chemical modifications-historical outline. Polimery 47:310-315

2. (2017) Analysis of European plastics production, demand and waste data. https://www.plasticseurope.org/en/resources/publi cations/274-plastics-facts-2017. Accessed 20 Sept 2018

3. Gallo F, Fossi C, Weber R et al (2018) Marine litter plastics and microplastics and their toxic chemicals components: the need for urgent preventive measures. Environ Sci Eur 30(1):13. https://doi. org/10.1186/s12302-018-0139-z

4. Avio CG, Gorbi S, Regoli F (2017) Plastics and microplastics in the oceans: from emerging pollutants to emerged threat. Mar Environ Res 128:2-11. https://doi.org/10.1016/j.maren vres.2016.05.012

5. Alshehrei F (2017) Biodegradation of synthetic and natural plastic by microorganisms. J Appl Environ Microbiol 5:8-19. https://doi. org/10.12691/jaem-5-1-2

6. Grabowska B (2010) Biodegradation of polymer materials. Arch Foundry Eng 10:57-60

7. Stępień AE (2011) Microbiological degradation of polyurethane materials. Polimery 56:716-720

8. Zarfl C, Matthies M (2010) Are marine plastic particles transport vectors for organic pollutants to the Arctic? Mar Pollut Bull 60:1810-1814. https://doi.org/10.1016/j.marpolbul.2010.05.026

9. Obbard RW, Sadri S, Wong YQ et al (2014) Global warming releases microplastic legacy frozen in Arctic Sea ice. Earth's Future 2:315-320. https://doi.org/10.1002/2014EF000240

10. Goldstein MC, Rosenberg M, Cheng L (2012) Increased oceanic microplastic debris enhances oviposition in an endemic pelagic insect. Biol Lett 8:817-820. https://doi.org/10.1098/ rsbl.2012.0298

11. Barnes D, Walters A, Gonçalves L (2010) Macroplastics at sea around Antarctica. Mar Environ Res 70:250-252. https://doi. org/10.1016/j.marenvres.2010.05.006

12. Lusher A, Milian GH, O'Brien J et al (2015) Microplastic and macroplastic ingestion by a deep diving, oceanic cetacean: the True's beaked whale Mesoplodon mirus. Environ Pollut 199:85191. https://doi.org/10.1016/j.envpol.2015.01.023

13. Bergmann M, Klages M (2012) Increase of litter at the Arctic deep-sea observatory HAUSGARTEN. Mar Pollut Bull 64:2734 2741. https://doi.org/10.1016/j.marpolbul.2012.09.018

14. Mallory ML (2006) The northern fulmar (Fulmarus glacialis) in Arctic Canada: ecology, threats, and what it tells us about marine environmental conditions. Environ Rev 14:187-216. https://doi. org/10.1139/a06-003

15. Provencher JF, Gaston AJ, Mallory ML (2009) Evidence for increased ingestion of plastics by northern fulmars (Fulmarus glacialisl) in the Canadian Arctic. Mar Pollut Bull 58:1092-1095. https://doi.org/10.1016/j.marpolbul.2009.04.002 
16. Ryan PG (1987) The effects of ingested plastic on seabirds: correlations between plastic load and body condition. Environ Pollut 46:119-125. https://doi.org/10.1016/0269-7491(87)90197-7

17. Andrady AL (2011) Microplastics in the marine environment. Mar Pollut Bull 62:1596-1605. https://doi.org/10.1016/j.marpo lbul.2011.05.030

18. Liebezeit G, Dubaish F (2012) Microplastics in beaches of the East Frisian islands Spiekeroog and Kachelotplate. Bull Environ Contam Toxicol 89:213-217. https://doi.org/10.1007/s0012 8-012-0642-7

19. Rochman C, Kross S, Armstrong J et al (2015) Scientific evidence supports a ban on microbeads. Environ Sci Technol 49:1075910761. https://doi.org/10.1021/acs.est.5b03909

20. Godoy V, Martín-Lara MA, Calero M, Blázquez G (2019) Physical-chemical characterization of microplastics present in some exfoliating products from Spain. Mar Pollut Bul 139:91-99. https ://doi.org/10.1016/j.marpolbul.2018.12.026

21. Bayo J, Martínez A, Guillén M, Olmos S, Roca MJ, Alcolea A (2017) Microbeads in commercial facial cleansers: threatening the environment. Clean Soil Air Water 45(7):1-112017

22. Cheung PK, Fok L (2017) Characterisation of plastic microbeads in facial scrubs and their estimated emissions in Mainland China. Water Res 122:53-61

23. Lei K, Qiao F, Liu Q, Zhanliang W, Qi H, Cui S, Yue X, Deng Y, An L (2017) Microplastics releasing from personal care and cosmetic products in China. Mar Pollut Bull 123:122-126

24. Praveena S, Shaifuddin S, Akizuki S (2018) Exploration of microplastics from personal care and cosmetic products and its estimated emissions to marine environment: an evidence from Malaysia. Mar Pollut Bull 136:135-140

25. Pang X, Zhuang X, Tang Z, Chen X (2010) Polylactic acid (PLA): research, development and industrialization. Biotechnol J 5(11):1125-1136. https://doi.org/10.1002/biot.201000135

26. Wagner M, Scherer C, Alvarez-Muñoz D et al (2014) Microplastics in freshwater ecosystems: what we know and what we need to know. Environ Sci Eur 26:12. https://doi.org/10.1186/s1230 2-014-0012-7

27. (2013) Green paper on a European strategy on plastic waste in the environment Brussels. http://ec.europa.eu/transparency/regdoc/ rep/1/2013/EN/1-2013-123-EN-F1-1.Pdf. Accessed 21 Sept 2018

28. Gouin T, Avalos J, Brunning I et al (2015) Use of micro-plastic beads in cosmetic products in Europe and their estimated emissions to the North Sea environment. SOFW J 141:40-46

29. Hirst D, Bennett O (2017) Microbeads and microplastics in cosmetic and personal care products. Brief Pap 7510:1-16

30. House of Commons Library (2016) Microbeads and microplastics in cosmetic and personal care products. http://researchbriefin gs.files.parliament.uk/documents/CBP-7510/CBP-7510.pdf. Accessed 21 Sept 2018

31. (2017) Environmental impact of microplastics fourth report of session 2016-17. https://publications.parliament.uk/pa/cm201 617/cmselect/cmenvaud/179/179.pdf. Accessed 21 Sept 2018

32. Guerranti C, Martellini T, Perra G, Scopetani C, Cincinelli A (2019) Microplastics in cosmetics: environmental issues and needs for global bans. Environ Toxicol Pharmacol 68:75-79. https ://doi.org/10.1016/j.etap.2019.03.007 